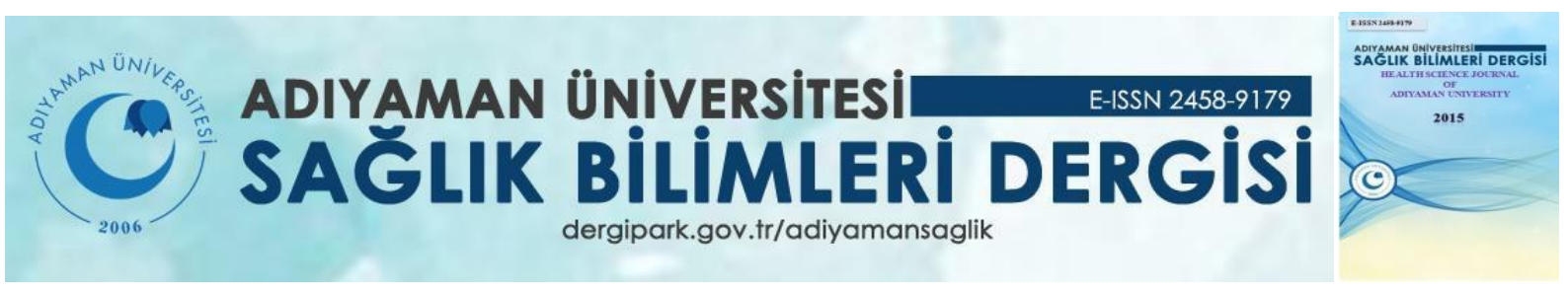

Derleme/ Review

\title{
Pediatrik Yoğun Bakım Ünitelerindeki (PYBÜ) Deliryum Hastalarında Düşme Riski ve Bu Amaçla Kullanılan Ölçekler
}

\begin{abstract}
Abdullah Sarman ${ }^{1}$
${ }^{1}$ Bingöl Üniversitesi, Sağlık Hizmetleri Meslek Yüksekokulu, İlk ve Acil Yardım Programı Recep Tayip Erdoğan Mah. Üniversite Cad. No: 1, Kat: 3, Oda No: A3-05 Posta Kodu: 12000 Bingöl/TÜRKIYYE / ORCID: 0000-0002$5081-4593$
\end{abstract}

ÖZ

Deliryum, hızlı başlayan, dalgalı seyir gösteren, çok farklı nedenlerden dolayı ortaya çıkan, bilinç, algılama, düşünce, uyku-uyanıklık döngüsü değişimlerinin eşlik ettiği bir klinik sendromdur. Düşmeler genellikle hastanede yatan çocuklarda meydana gelen önlenebilir olaylar olarak tanımlanabilir. Pediatrik yoğun bakımlar düşme olaylarının sıklıkla yaşanabildiği ortamlardır. Deliryumdaki hastalarda oluşan bu tür bilinç değişikleri düşme açısından risk oluşturur. Bilinç değişimleriyle beraber gelişebilen düşme riskine yönelik olarak çeşitli pediatrik düşme riski değerlendirme ölçekleri geliştirilmiştir. Yoğun bakım ve klinik ortamlarda hastalarla yakın ilişki içerisinde olan hemşirelerin hastalardaki deliryum ve bilinç değişikliklerini önceden tanımlaması önemlidir. Bu derleme makalede literatürde çeşitli yaş gruplarında yaygın olarak kullanılan ölçme araçlarının özellikleri ve kullanım amaçları konusunda bilgi verilmesi amaçlanmaktadır.

Anahtar kelimeler: Pediatrik Hasta, Deliryum, Düşme Riski, Tanı Ölçeği, Pediatrik Yoğun Bakım Ünitesi, Düşme Riski Değerlendirme Aracı

\section{Fall Risk for Delirium Patients in Pediatric Intensive Care Units (PICUs) and Risks Scales Used for This Reason}

\begin{abstract}
Delirium is a fulminant disorder with a fluctuating course and a wide range of underlying causes. It is a commonly characterized by altered mental status, disturbance of consciousness and cognition, as well as disruptions in sleepwake cycle. Falls can be described often preventable events that happen in hospitalized children. Pediatric intensive care units are the places where falls occur frequently. Such changes in consciousness in patients with delirium pose a risk for falls. Various pediatric fall risk assessment scales have been developed for falling risk that may develop with changes in consciousness. It is important that nurses who are in close contact with patients in intensive care and clinical settings predefined delirium and consciousness changes in patients. In this review article, it is aimed to give information about the characteristics and purposes of the measurement instruments commonly used in various age groups in the literature.
\end{abstract}

Keywords: Child Patient, Delirium, Falling Risk, Diagnostic Scale, Pediatric Intensive Care Units, Fall Risk Assessment Tool

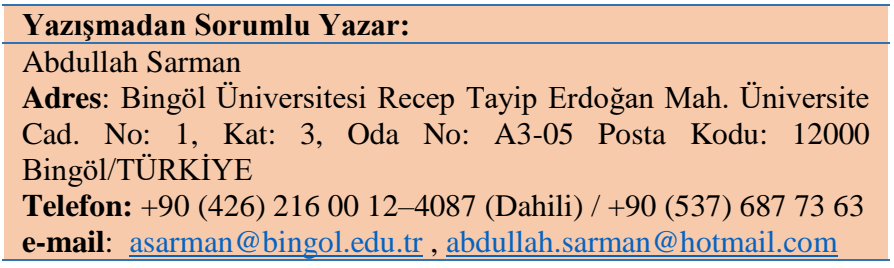

Doi: 10.30569.adiyamansaglik.609711

Atıf Gösterimi/How to Cite: Sarman A. Pediatrik Yoğun Bakım Ünitelerindeki (PYBÜ) Deliryum Hastalarında Düşme Riski ve $\mathrm{Bu}$ Amaçla Kullanılan Ölçekler. Adıyaman Üni. Sağlık Bilimleri Derg. 2019; 5(3);1814-1828. doi:10.30569.adiyamansaglik.609711 


\section{GíRiş}

Deliryum, hastalarda bilinç değişiklikleri ve düşüncelerde gün içinde dalgalanmaların yaşanabildiği ve alg1 düzeyinde bozulmayla meydana gelen, çoğunlukla geçici olan bir rahatsızlıktır (1). Erişkin hastalar arasındaki deliryumun yüksek morbidite, rezidüel bilişsel ve fonksiyonel sorunlar aynı zamanda artmış mortalite oranları ile ilişkili olduğu belirtilmektedir (2). Bu durum, çoğunlukla sağlık bakımının etkin olarak sürdürüldüğü ortamlarda görülür. Özellikle yoğun bakım ünitelerinde (YBÜ) ve palyatif bakım sunulan özellikli sağlık hizmetlerinde daha yüksek oranlarda meydana geldiği belirtilmiştir (3-5). Literatürde deliryum vakalarının önemli bir olgu olduğu belirtilerek yatarak tedavi gören yetişkinlerin yaklaşık \% 30'unu, yoğun bakım ünitesindeki yetişkinlerin \% 50'sini ve ölümcül hastalıklar nedeniyle tedavi gören yetişkinlerin \% 80'ini etkilediği ifade edilmiştir (6). Semptomlar yönüyle incelendiğinde deliryum genel olarak 3 türe ayrılmaktadır. Bunlar;

- Hiperaktif deliryum,

- Hipoaktif deliryum ve

- Mix (karışık) tip deliryum olarak sıralanmaktadır (7).

Pediatrik deliryum, ilk olarak 1957 yılında "Çocuk Psikiyatri” adlı dergide, o güne kadar otizm ile ilgili çalışmaları ile tanınan Amerikalı bir psikiyatrist olan Leo Kanner tarafından tanımlanmış ve ilk kez 1972'de pediatri literatüründe yer almıştır (8). Çocukluk çağında meydana gelen deliryum uzun süredir ihmal edilmiş bir araştırma alanı olmasına rağmen, yeni yapılan çalışmalar ve araştırma sonuçları çocuklarda deliryumun birçok yönden yetişkinlerdeki verilere benzer şekilde yaygın olarak görüldüğünü ve çeşitli nörolojik ve bilişsel problemlere neden olabildiğini göstermektedir. Pediatri yoğun bakım ünitelerinde tedavi gören çocuk ve ergenlerde deliryumun \% 65 oranında gözlenen bir oranı olduğu belirtilerek psikiyatrik tanı alan çocuk hastalar ve ergenler arasında \% 8 gibi bir yaygınlığının olduğu belirtilmektedir (913). Deliryumlu çocuk hastalarda klinik seyrin niteliğini belirleyen çalışmalarda deliryumun belirlenmesinden beş hafta sonra hastaların genelinde algısal düzeyde yaşanabilen, motor beceri sorunları ve davranışsal problemlerin gözlenebildiği görülmüştür. Araştırma sonuçları bu tür klinik belirtilerin birbirleriyle ilişkili olduğunu göstermektedir $(14,15)$.

Deliryumun en yaygın özelliği hastalarda gözlenen bazı spesifik belirtiler ve ruhsal durumda yaşanan bozulmadır. Hatherill ve arkadaşları (2010), tarafından yapılan bir çalışmada deliryumlu çocuk hastaların \% 22'sinin deliryum sendromunun başlamasından birkaç gün içinde apati, disfori ve yoksunluk ile karakterize belirgin bir hastalık süreci sergilemeye 
başladığı bildirilmiştir. $\mathrm{Bu}$ çalışmada vakaların psikomotor aktivite temelinde sınıflandırıldığında hiperaktif deliryumlu çocuk hastaların uyaranlara yanıt verebilirliğinin $\operatorname{arttığı,~motor~aktivitelerinin~yükseldiği,~hastalar~tarafından~sıklıkla~halüsinasyonlar~ve~sanrılar~}$ görüldüğü, buna karşın hipoaktif deliryumlu çocuklarda uyaranlara yanıt kabiliyetinin azaldığı, uyanıklık düzeyinin düştüğü ve motor aktivitenin yavaşladığı belirtilmiştir. Mix (karışık) tipte deliryumlu çocuk hastalarda ise tipik olarak, tek bir deliryum bölümü içinde bu iki kutup arasında dalgalanmaların meydana gelebildiği ifade edilmiştir (16).

Kelly ve Frosch (2012), tarafından deliryumlu çocuk hastalar üzerinde sendrom süresince meydana gelen semptomların özelliklerinin tür ve niteliğini belirlemeye yönelik yapılan çalışmada ise deliryum belirtilerinin yetişkinlere göre farklılıklar gösterebildiği, hastaların hem hipoaktif hem de hiperaktif semptomatolojiye uygun belirtiler sergiledikleri belirtilmiştir (6).

Hastaların biliş düzeylerinde yaşanan ani dalgalanmalar deliryumlu çocuk hastalarda düşme açısından risk oluşturabilmektedir. Hastanede yatan hastalarda, özellikle de yoğun bakımlarda düşme oranının, tüm hasta grupları için Amerika Birleşik Devletleri'nde binde 3,44-7,6 arasında değiştiği belirtilmektedir (17). Çocuk hastaların değerlendirildiği vakalarda ise bu oranın binde 0,57 ile 1,36 arasında değiştiği gösterilmiştir (18). Bu nedenle birçok hastane sağlık hizmetlerinin kalitesinin bir göstergesi olarak, birimlerinde meydana gelen hasta düşme oranlarını azaltmak için gerekli tüm önlemleri almaya çalışmaktadır $(19,20)$. Düşmeler genellikle hastanede yatan çocuklarda meydana gelen önlenebilir olaylardır. Düşmeler farklı fiziksel ve çevresel faktörlerden kaynaklanabilir (21). Deliryum meydana gelen vakalarda düşme vakaları çoğu kez çocukların biliş bulanıklıkları nedeniyle oluşabildiği için bu durum hastalarda düşme riskini arttırmaktadır $(22,23)$. Bu tür olumsuz olaylar karşısında çocukların zarar görmesini engellemek amacıyla hastaların erken dönemde bir tarama sürecinden geçirilerek, önleme programları aracılığıyla düşme riski taşıyan hastaları belirlemek son derece önemli olacaktır (24). Düşme riski değerlendirme araçları ve ölçekleri kullanılarak beklenen düşme vakaları öncesinde tespit edilebilir. Dolayısıyla yaşanabilecek travmatik durumlar ve hasta açısından oluşabilecek olumsuzluklar önlenebilir (25). Bu çalışmada, deliryumlu çocuk hastalardaki düşme olasılığını saptamak amacıyla kullanılan risk tanılama ve değerlendirme ölçeklerinin incelenmesi amaçlanmıştır. 


\section{DELIRYUMLU ÇOCUK HASTALARDAKİ DÜŞME RİSKİ TANILAMA VE DEĞERLENDİRME ÖLÇEKLERİ}

\section{BUÇH Çocuk Hastalar İçin Düşme Riski Tanılama Ölçeği}

$\mathrm{Bu}$ ölçek toplamda 11 maddeden oluşan ve çocuk hastalardaki düşme riskini belirlemeye yönelik bir ölçektir. Ölçeğin her bir maddesi hastanın sorun seviyesinin şiddetine ve düzeyine göre derecelendirilmiştir. Düşme riski olarak toplamda 11 madde belirlenmiştir. Bunlar; çocuğun tedavi gördüğü klinik, yaşı, düşme öyküsü, mental durumu, hastalığa ilişkin tanısı, yaşamsal bulguları, tedavisi, mobilizasyonda kısıtlılık hali, sedasyon durumu, bakım veren kişiler, klinik uygulamalar ve çevresel faktörlerden oluşmaktadır. Bu ölçek, Behçet Uz Çocuk Hastanesi'nde kullanılmak üzere geliştirilmiştir. Ölçeğin toplam korelasyon katsayısının 0,1750,610 arasında olduğu bulunmuştur. Ölçeğin kesim noktası 16,5 puan olarak belirtilmektedir. Demir ve arkadaşları (2013), tarafından yapılan duyarlılık ölçümlerinde ölçeğin geçerliğinin 0,833 ve güvenirliğinin 0,496 olduğu saptanmıştır. Çocuk hastalar için BUÇH Düşme Riski Tanılama Ölçeği’nden 16,5 puan ve üstü alan çocukların yüksek düşme riskine sahip olarak değerlendirileceği belirtilmektedir (Tablo 1) $(26,27)$. 
Tablo 1: BUÇH Çocuk Hastalar İçin Düşme Riski Tanılama Ölçeği

\begin{tabular}{|l|c|}
\hline 1. Klinikler & Puan \\
\hline Süt Oyun Çocuğu 1-2 Servisleri \\
Acil Servis & \\
Pediatri Yoğun Bakım & \\
Cerrahi Yoğun Bakım & \\
Hematoloji-Onkoloji Servisi & \\
Kardiyoloji Servisi & \\
Kalp Damar Cerrahisi Servisi & \\
Uyandırma Odası & 3 Puan ( ) \\
EEG Birimi & \\
Ameliyathane & \\
Yanık Servisi & \\
Cerrahi Servisi & \\
Fizik Tedavi Rehabilitasyon Ünitesi & \\
Diyaliz Ünitesi & \\
\hline Prematüre Yoğun Bakım & \\
Yenidoğan Yoğun Bakım & \\
Prematüre Servisi & \\
Yenidoğan Servisi & \\
İntaniye Servisi & \\
Ortopedi Servisi & \\
Emzirme Odaları & 2 Puan ( ) \\
\hline Büyük Çocuk Servisi & \\
Laboratuvarlar & Puan ( ) \\
\hline 2. Yaş & \\
\hline 3 yaş ve altı & Puan ( ) \\
\hline 4-6 yaş arası & Puan ( ) \\
\hline 7-12 yaş & \\
\hline 13 yaş ve üstü & Puan ( ) \\
\hline 3. Düşme Öyküsü & \\
\hline Düşme öyküsü var & \\
\hline Düşme öyküsü yok & \\
\hline 4. Tanısı & \\
\hline Birden fazla hastalık tanısı & \\
\hline
\end{tabular}

Nörolojik hastalık tanıs1-

Davranım Bozukluğu (Hiperaktivite, 4 Puan ()

ajitasyon vb.)

Kas-iskelet sistemi hastalık tanısı

(Ampute-doğuştan uzuv yokluğu)

Oksijenasyonda bozulma (solunum

hastalıkları, dehitratasyon, anemi,

anoreksiya, senkop/baș dönmesi vb.)

Diğer Tanılar

\section{Mental Durum}

Oryantasyon bozuk (konfüze,

disoryante, deliryum vb.)

Oryante

6. Yaşam Bulguları

Unstabil

Stabil

3 Puan $(0)$

3 Puan ( )

\section{Tedavi}

Coklu ilaç kullanım

(Sedatifler, Hipnotikler, Barbituratlar,

Fenatiazin, Antidepresanlar,

Narkotikler, Laksatifler/Diüretik

türündeki ilaçlardan birden fazla

kullanım)

Așağıdaki ilaçlardan birini kullanma

Sedatifler, Hipnotikler, Barbituratlar,

Fenatiazin, Antidepresanlar,

2 Puan ( )

2 Puan ( )

1 Puan ()

Narkotikler, Laksatifler/Diüretikler

Diğer tedaviler/tedavi olmaması

8. Sedasyon Alma

İşlem öncesi/sonrası sedasyon

2 Puan ( )

\begin{tabular}{|l|l|}
\hline Sedasyon yok & 2 Puan ( ) \\
\hline Mobilizasyonda KIsitlama Olması & 1 Puan ( ) \\
\hline
\end{tabular}

9. Mobilizasyonda Kisıtlama Olması
Kisitlayıcı durum/cihaz olması

(Tekerlekli sandalye kullanımı, yürütec

kullanımı, görme ve işitme yetersizliği

damar yolunun olması vb.)

Kisitlayıcı durum ve/veya cihaz yok 1 Puan ( )

10. Bakım Veren Kiși

Refakatçisi olmayan hasta

Annesi dişında biri refakat ediyor

3 Puan ( )

Annesi refakat ediyor

11. Klinik Uygulamalar-Banyo

Banyo yapma

Banyo uygulaması yok

12. Klinik Uygulamalar-Aclık

İşlem öncesi/sonrası aç olma

Açlık durumu yok

13. Klinik Uygulamalar-Tespit

Tespit edilme

Tespit yok

\section{Eliminasyon}

Tuvalete s1k gidiyor

Eliminasyonda sorun

\section{Uyku örüntüsü}

Uykusuzluk/uyku düzensizliğ

Uyku örüntüsünde sorun yok

16. Çevresel Faktörler-Aydınlanma

Kliniğin aydınlanma durumu yetersiz

Kliniğin aydınlanma durumu yeterli

17. Cevresel Faktörler - Zemin

Zemin kaygan

Zemin kaygan değil

Puan ()

1 Puan ()

18. Cevresel Faktörler - Yatak

Kullanılan yatak (bebek yatağı, genç

yatağ1, yetişkin yatağı, puset) uygun

değil

Kullanılan yatak (bebek yatağ 1 , genç

yatağ 1 , yetişkin yatağ1, puset) uygun 


\section{Çocuk Hastalarda Genel Risk Değerlendirmesi Düşme Ölçeği (GRAF-PIF)}

$\mathrm{Bu}$ ölçek çeşitli hastalıklar nedeniyle kliniklerde yatan çocuk hastalarda düşme öyküsü, hastanede kalış süresi, tedavi, ortopedik sorunlar ve kas-iskelet sistemi, epilepsi gibi hastalıkların varlığının sorgulandığı maddeleri ele alarak kullanılmakta ve beş maddeden oluşmaktadır. Ölçekten toplamda 2 veya daha fazla puan alınması, çocuğun düşme riskinin yüksek olduğunu ve yüksek riskli hastalara uygulanan düşme önleme stratejilerinin gerekliliğini gösterir. Yapılan analizlerde bu ölçeğin seçiciliğinin yüksek olduğu ve çocuk hastalardaki düşmelerin \% 59,3'ünü önceden tanılayabildiği bildirilmiştir. GRAF-PIF'in doğruluğu, düşme yaşayan çocuklarda ve düşme riski protokollerinin uygulanmasından önceki altı yıl boyunca, düşmeyen çocuklar ile retrospektif vaka kontrol çalışmalarıyla değerlendirilmiştir $(27,28)$.

\section{Humpty Dumpty Düşme Ölçeği (HDFS)}

Bu ölçek, Miami, Florida'daki Miami Çocuk Hastanesi'nde birden fazla sağlık çalışanının koordinasyonunu sağlayan bir hemşire ekibi tarafından tasarlanan tarama aracıdır. Hastane ekibi, ölçeğin parametrelerini tanımlamak için süreç iyileştirme verilerini kullanmıştır. Bu araç, biri cerrahi tedavi için sedasyon/anestezi alarak yataklı ortamlarda tedavi olan hastalarda geçerli parametreleri içeren, diğeri ayaktan tedavi gören hastaları kapsayan verilerin değerlendirildiği iki bölümden oluşmaktadır. Ölçeğin, hastane acil servislerinde, doğumhanelerde, yenidoğan yoğun bakım ünitesi, çocuk sağlığ 1 ve hastalıkları klinikleri gibi tüm yataklı tedavi ünitelerinde uygulanması mümkündür. Ölçeğin yaş, cinsiyet, tanı, biliş düzeyinde bozulmalar, çevresel faktörler, cerrahi müdahale, sedasyon/anesteziye cevap, ilaç kullanımı gibi çeşitli alt bölümleri bulunmaktadır. $\mathrm{Bu}$ bölümlerin her birine bir puan verilir ve tüm bölümlerden elde edilen puanlar ölçek toplam puanının belirlenmesi için sıralanır. 12 veya daha yüksek puan alan hastalar, yüksek riskli olarak kabul edilir ve hastayı korumak için bir protokol uygulanması gereklidir (Tablo 2) (29,30). Bu ölçek, 2014 yılında bir hizmet içi programın uygulanmasının ardından, çocuk hastaların tedavi gördüğü ünitelerde bir tarama aracı olarak kullanılmış; hemşirelerin HDFS ölçeğini doğru şekilde kullandıkları ve buna bağlı olarak düşme önlemlerini kliniklerde etkin bir biçimde uyguladıkları gözlenmiştir. Aynı çalışma sonuçları HDFS ölçeğinin kullanımı öncesinde alınan bir eğitim sonrasında hemşireler tarafından kullanıldığında klinik uygulamalar için yararlı bir ölçüm aracı olduğu ve hemşirelerin düşme riski olan çocuk hastalar hakkındaki farkındalıklarını artırdığını göstermiştir. 
Tablo 2: Humpty Dumpty Düşme Ölçeği (HDFS)

\begin{tabular}{|c|c|c|}
\hline Parameter & Criteria & $\begin{array}{c}\text { Score } \\
\text { (Circle) }\end{array}$ \\
\hline \multicolumn{3}{|l|}{ Age } \\
\hline & Less than 3 years old & 4 \\
\hline & 3 to less than 7 years old & 3 \\
\hline & 7 to less than 13 years old & 2 \\
\hline & 13 years old and above & $\mathbf{1}$ \\
\hline \multicolumn{3}{|l|}{ Gender } \\
\hline & Male & 2 \\
\hline & Female & $\mathbf{1}$ \\
\hline \multicolumn{3}{|l|}{ Diagnosis } \\
\hline & Neurological Diagnosis & 4 \\
\hline & $\begin{array}{l}\text { Alterations in Oxygenation (Respiratory Diagnosis, } \\
\text { Dehydration, Anemia, Anorexia, Syncope/Dizziness, etc.) }\end{array}$ & 3 \\
\hline & Psych/Behavioral Disorders & 2 \\
\hline & Other Diagnosis & 1 \\
\hline \multicolumn{3}{|l|}{\begin{tabular}{|l|} 
Cognitive Impairments \\
\end{tabular}} \\
\hline & Not Aware of Limitations & 3 \\
\hline & Forget Limitations & 2 \\
\hline & Oriented to own Ability & 1 \\
\hline \multicolumn{3}{|l|}{\begin{tabular}{|l|} 
Environmental Factors \\
\end{tabular}} \\
\hline & History of Falls or Infant-Toddler Placed in Bed & 4 \\
\hline & $\begin{array}{c}\text { Patient uses assistive devices or Infant Toddler in Crib or } \\
\text { Furniture/Lighting (Tripled Room) }\end{array}$ & 3 \\
\hline & Patient Placed in Bed & 2 \\
\hline & Outpatient Area & 1 \\
\hline \multirow[t]{4}{*}{\begin{tabular}{|c|} 
Response to \\
Surgery/Sedation/Anest \\
\end{tabular}} & & \\
\hline & Within 24 hours & 3 \\
\hline & Within 48 hours & 2 \\
\hline & More than 48 hours/None & 1 \\
\hline \multicolumn{3}{|l|}{ Medication Usage } \\
\hline & $\begin{array}{c}\text { Multiple Usage of: } \\
\text { Sedatives (excluding ICU patients sedated and paralyzed) } \\
\text { Hypnotics Barbiturates Phenothiazine's Antidepressants } \\
\text { Laxatives/Diuretics Narcotics }\end{array}$ & 3 \\
\hline & One of the meds listed above & 2 \\
\hline & Other Medications/None & 1 \\
\hline & Total & \\
\hline
\end{tabular}

\section{CHAMPS Çocuk Düşme Riski Değerlendirme Ölçeği}

CHAMPS Çocuk Düşme Riski Değerlendirme Ölçeği, altı alt boyutta düşme riskini tanılamaya yardımcı bir ölçektir. Ölçek, düşmeleri belirlemede orta düzey güce sahiptir. $\mathrm{Bu}$ ölçeğin geçerlik ve güvenirlik çalışması Razmus ve Davis (2012), tarafından yapılmıştır. Ölçeğin duyarlılığ 0,75 ve seçiciliği 0,79 'dur (31). 


\section{Pediatrik Düşme Riski Değerlendirme Ölçeği (PFRA)}

Pediatrik Düşme Riski Değerlendirme Ölçeği (PFRA), toplamda 10 maddeden oluşan yüksek düşme riskli çocuk hastaların değerlendirilmesi amacıyla geliştirilmiş bir ölçektir. Bu ölçek, çocuklarda meydana gelen gereksiz düşmelerin önlenmesini, muhtemel düşme vakalarının erken dönemde tespitini ve yüksek riskli olarak değerlendirilen çocuklarda düşmeyi önlemeyi hedeflemektedir. Ölçeğin geçerlik ve güvenirliği Ryan-Wenger ve arkadaşları (2012), tarafından retrospektif olarak vaka kontrol tasarımında değerlendirilmiştir (32). Ölçeğin hassasiyeti \% 95,1 olmasına rağmen; \% 53,2 pozitif ve \% 56,5 negatif öngörü değerleri olduğundan doğruluk seviyesinin kabul edilemez derecede düşük olduğu belirtilmiştir. PFRA'nın yaygın olarak kullanılan çocuk düşme riski ölçekleri gibi yeterli hassasiyete sahip olmadığı ifade edilmiştir.

\section{I'M SAFE Risk Değerlendirme Ölçeği}

Neiman ve arkadaşları (2011), tarafından geliştirilen bu ölçüm aracı GRAF-PIF'den sonra modellenmiştir. Bu ölçek hastanın ilaçları, sedasyon/anestezi durumu, tanısı, hastalık öyküsü ve bakım ortamını değerlendirir. Geçerlik ve güvenirlik çalışmasında ölçekte kullanılan değişkenlerin elektronik tıbbi kayıtlarda kolayca bulunabilen veriler ve klinik uzmanlar tarafından belirlenen düşmelerle en yüksek düzeyde korelasyon gösterdiği bulunmuştur (22). $\mathrm{Bu}$ çalışmada ölçeğin içsel düşme oranlarının önemli ölçüde azaldığ 1 (uygulama öncesi: 0,67, uygulama sonrası: 0,51) belirtilmiştir (33).

\section{İtaki Düşme Riski Değerlendirme Ölçeği}

On yedi yaş ve üzerindeki hastalar için oluşturulmuş olan ölçek, hastanın demografik bilgilerini, düşme riskiyle ilgili değerlendirme yapılma nedenini içermektedir. Ölçekte majör ve minör risk faktörleri başlıkları altında toplam 19 madde bulunmaktadır. Ölçek skoru tüm maddelerin aldığı puanlar toplanarak oluşturulur. Toplam skor 0-4 puan arasında ise hasta düşük riskli, 5 puan ve üzerinde ise yüksek riskli kabul edilir (Tablo 3) (34-36). 
Tablo 3: İtaki Düşme Riski Değerlendirme Ölçeği

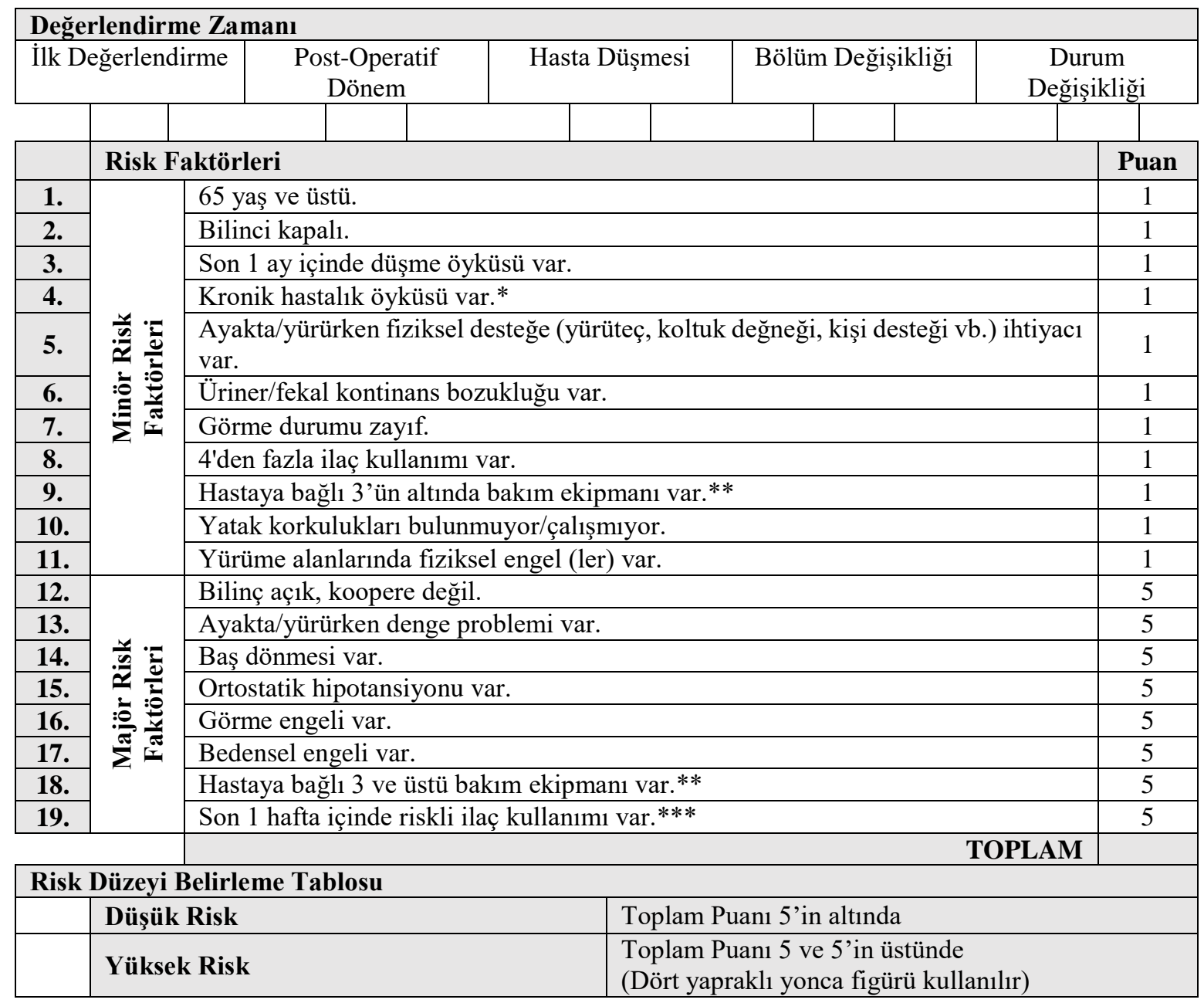

Değerlendirmeyi yapan Hemşire

Adı-Soyadı:

İmza:

NOT: Düşmelerin önlenmesine yönelik alınacak önlemler hastada var olan risk faktörlerine göre belirlenmelidir

\section{Harizmi Düşme Riski Ölçeği}

0-16 yaş arasındaki çocuk hastalar için oluşturulmuş olan bu düşme riski değerlendirme ölçeğinde hasta demografik bilgileri ve değerlendirmenin yapılma nedenini belirten 9 madde bulunmaktadır. Ölçek skoru tüm maddelerin puanları toplanarak oluşturulur. Toplam skor 0-14 puan arasında ise düşük riskli, 15 puan ve üzerinde ise yüksek riskli kabul edilir. Sağlık Bakanlığı tarafından geliştirilmesine rağmen çocuk hastalarda geçerlik ve güvenirliğine ilişkin net bir yayına ulaşılamamıştır (Tablo 4) $(26,37,38)$. 
Tablo 4: Harizmi Düşme Riski Ölçeği

\begin{tabular}{|c|c|c|c|c|c|c|c|c|}
\hline \multicolumn{9}{|c|}{ Değerlendirme Gerekçesi/Numarası } \\
\hline \multicolumn{2}{|c|}{$\begin{array}{c}\text { 1. İlk } \\
\text { Değerlendirme } \\
\end{array}$} & \multicolumn{2}{|c|}{$\begin{array}{l}\text { 2. Post-Operatif } \\
\text { Dönem }\end{array}$} & \multicolumn{2}{|c|}{ 3. Hasta Düşmesi } & \multicolumn{2}{|c|}{$\begin{array}{l}\text { 4. Bölüm } \\
\text { Değişikliği }\end{array}$} & $\begin{array}{l}\text { 5. Durum } \\
\text { Değişikliği }\end{array}$ \\
\hline \multirow{5}{*}{\multicolumn{3}{|c|}{ Risk Faktörleri }} & \multicolumn{6}{|c|}{ Değerlendirmeler } \\
\hline & & & \multicolumn{6}{|c|}{ Değerlendirme numarası } \\
\hline & & & & .. & .. & & & .. \\
\hline & & & & rih: & Tarih: & Tarih: & Tarih: & Tarih: \\
\hline & & & &.... &....$/ \ldots$ & $. / \ldots / \ldots$ & $. . / \ldots / .$. & $. . / \ldots / \ldots$ \\
\hline 1. & \multicolumn{2}{|c|}{$\begin{array}{l}\text { Nörolojik } \\
\text { hastalı̆̆1/semptomu var }\end{array}$} & \multicolumn{2}{|c|}{5} & 5 & 5 & 5 & 5 \\
\hline 2. & \multicolumn{2}{|c|}{$\begin{array}{l}\text { Oksijenlenme değişikliği } \\
\text { var }\end{array}$} & \multicolumn{2}{|c|}{5} & 5 & 5 & 5 & 5 \\
\hline 3. & \multicolumn{2}{|c|}{\begin{tabular}{|l|l} 
Düşme riski açısından \\
özellikli \\
hastalığı/semptomu var \\
\end{tabular}} & \multicolumn{2}{|c|}{15} & 15 & 15 & 15 & 15 \\
\hline 4. & \multicolumn{2}{|c|}{\begin{tabular}{|l}
$\begin{array}{l}\text { Hasta uygun yatakta } \\
\text { yatırılmiyor }\end{array}$ \\
\end{tabular}} & \multicolumn{2}{|c|}{5} & 5 & 5 & 5 & 5 \\
\hline 5. & \multicolumn{2}{|c|}{ Görme engeli var } & & 5 & 5 & 5 & 5 & 5 \\
\hline 6. & \multicolumn{2}{|c|}{$\begin{array}{l}\text { Hastaya bağlı } 3 \text { ve üstünde } \\
\text { bakım ekipmanı var }\end{array}$} & \multicolumn{2}{|c|}{5} & 5 & 5 & 5 & 5 \\
\hline 7. & \multicolumn{2}{|c|}{\begin{tabular}{|l|} 
Ayakta/yürürken fiziksel \\
desteğe (yürüteç, koltuk \\
değneği, kişi desteği vb.) \\
ihtiyacı var \\
\end{tabular}} & \multicolumn{2}{|c|}{5} & 5 & 5 & 5 & 5 \\
\hline 8. & \multicolumn{2}{|c|}{$\begin{array}{l}\text { Hasta post-op. ilk } 48 \text { saatlik } \\
\text { dönemde. }\end{array}$} & & 5 & 5 & 5 & 5 & 5 \\
\hline 9. & \multicolumn{2}{|c|}{ Riskli ilaç kullanımı var } & & 5 & 5 & 5 & 5 & 5 \\
\hline & & lam Puan & & & & & & \\
\hline & Değerlenc & $\begin{array}{l}\text { eyi Yapan } \\
\text { Hemşire: }\end{array}$ & & & & & & \\
\hline & & iksek Risk & $\begin{array}{l}\text { Topl } \\
\text { bu ha }\end{array}$ & & $\begin{array}{l}\text { ve üstünd } \\
\text { irt Yapra }\end{array}$ & $\begin{array}{l}\text { hastalar } \\
\text { onca" se }\end{array}$ & $\begin{array}{l}\text { ek riskli k } \\
\text { ü kullanıll }\end{array}$ & $\begin{array}{l}\text { abul edilmeli ve } \\
\text { malıdır. }\end{array}$ \\
\hline
\end{tabular}

\section{TARTIŞMA}

Hemşireler ve diğer sağlık çalışanlarının deliryumlu çocuk hastalara ilişkin düşünceleri ve ön yargıları deliryumun yönetilmesini olumsuz olarak etkileyebilmektedir. Yoğun bakım ünitelerinde çalışan sağlık personelleri deliryumu çoğu kez yoğun bakım hastalarında meydana gelen normal bir durum olarak değerlendirerek izlemleri göz ardı edebilmektedir (39). Deliryumun erken dönemde tespit edilerek yönetilmesi için hemşirelerin deliryum, risk faktörleri, değerlendirme ve bakım uygulamaları ile ilgili bilgi ve beceri sahibi olması gerekmektedir (40). 
Yoğun bakım ünitelerindeki çocuk hastalar deliryum açısından rutin olarak standart bir ölçüm aracı yardımıyla değerlendirilmelidir. Hemşirelerin sıklıkla kullandığı ve deliryum için klinik uygulama rehberlerinde önerilen ölçüm araçları çeşitlilik göstermektedir. Devlin ve arkadaşları (2008), yaptığı çalışmada yoğun bakım hemşirelerinin yarısının hastaların değerlendirilmesinde kullanılan ölçeklerin karmaşıklığı nedeniyle bulundukları ünitelerde deliryum değerlendirmesi yapamadıkları belirtilmiştir (41). Wels (2012), Morandi ve Jackson (2011), Boot (2012), tarafından yapılan çalışmalarda deliryumlu hastaların bilinç değişiklikleri nedeniyle belirli aralıkla ve günün değişen saatlerinde sistematik olarak değerlendirilmeleri gerektiği belirtilmiştir. Çocuk yoğun bakım ünitelerinde risk grubunda yer alan hastalar 8-12 saatte bir deliryum açısından geçerlik ve güvenirliği yapılarak klinik ortamlarda denenmiş bir ölçüm aracıyla izlenmelidir (42-44).

Hemşire bakım verirken çocuk hastalardaki deliryumun çeşidine göre uygulamalarını planlamalıdır. Hiperaktif deliryumdaki çocuk hastalar davranışsal ve duygusal bozukluklar nedeniyle daha kolay fark edilebilirler. Hipoaktif deliryumun tanılanması ise daha zor olabilmektedir. Hipoaktif deliryumun prognozu daha kötü olduğu için, çeşitli ölçüm araçları yardımıyla erken dönemde tanılanması son derece önemlidir. Guo-hao ve Xiang-ming (2009), yoğun bakımlarda hipoaktif deliryumun psikiyatrik belirtilerle karıştırıldığı için, hemşirelerin hastalarında belli aralıklarla deliryum değerlendirmesi yapması gerektiğini belirtmiştir (45). Çalışma sonuçları güvenli bir ölçme aracılığıyla yapılan değerlendirmenin çocuk hastalarda deliryumu erken dönemde saptamayı kolaylaştırarak hastada oluşabilecek sorunların önlenebilmesini sağladığını göstermektedir. Ülkemizde kullanılan düşme riski değerlendirme ölçeklerin standardizasyonuyla ilgili çeşitli problemler olduğu düşünülmektedir. Düşme riski değerlendirme ölçeklerinin ülkemizin değer ve normlarına göre uyarlanmasında, öncelikli olarak evreni en iyi biçimde temsil edebilecek uygun örneklem gruplarının oluşturulması ve elde edilecek verilere göre ölçeklerin çeviri ve uygulamalarının yapılması gereklidir.

\section{SONUÇ}

Hastane ortamı, hem çocuklar hem de aileleri için tanıdık olmayan bir çevredir. Çocuk hastaların gerek hastanede gerekse tedavi sürecinde yaşadıkları olumsuzluklar düşme açısından sorun yaşamalarına neden olabilmektedir. Özellikle yoğun bakımlarda tedavi gören çocukların yaşayabildiği deliryum başta olmak üzere çeşitli psikiyatrik sorunlar ve bilinç değişiklikleri çeşitli ölçme ve değerlendirme araçlarıyla önceden tanımlandığında hastalara destekleyici önlemler uygulanarak düşmeye bağlı oluşabilecek sorunlar en aza indirgenebilecektir. 
Hemşireler pediatrik düşme riski değerlendirme ölçeklerini günlük bakımlarında, hastalarının düşme açısından değerlendirilmesinde kullanırlar ve hastanın düşmesini önlemek için kanıta dayalı müdahalelerin uygulanmasından sorumludurlar. Bazı düşme riski ölçekleri benzer değerlendirme özelliklerine sahip olsa da, bu araçlar belirli bir hasta popülasyonu için ayırıcı birtakım niteliklere sahiptirler. Her ne kadar düşme riski ve çocuk hastalara özgü müdahaleler hakkında literatürde çeşitli çalışmalar bulunsa da araştırmalar henüz başlangıç aşamasındadır ve kanıt düzeyleri istenilen düzeyde değildir. Güvenilir ve geçerli bir ölçüm aracının geliştirilmesi, araştırmacıların çok sayıda ve çeşitli özelliklere sahip çocuk hasta popülasyonunda kesinlik, doğruluk ve çalışma hatalarını belirleyebilecek araştırma tasarımlarını kullanmasını gerektirir. Ancak o zaman düşüş oranlarını ulusal ve uluslararası düzeyde etkin bir şekilde azaltabilir ve önleme yaklaşımlarında bir standardizasyon elde edilebilir.

Bu makalede, düşme riskinin bir ölçme ve değerlendirme aracıyla önceden değerlendirmesinin hastanede yatan çocuk hastalar için meydana gelebilecek düşme problemlerin önlenmesinde ve hasta güvenliğinin arttırılmasında kritik bir önemi olduğu görülmüştür.

\section{ÖNERİLER}

- Çocuk kliniklerinde kullanılan düşme riski değerlendirme ölçeklerinin seçiciliğinin yapılacak klinik çalışmalarla doğrulanması ve çalışmaların daha büyük örneklem gruplarıyla yinelenmesi,

- Çocuk yoğun bakım ünitelerinde algısal düzeyde değişim yaşayan, motor beceri sorunları görülen ve davranışsal problemleri olan tüm çocukların riskli hasta grubuna dahil edilerek düşme riski değerlendirme ölçekleri ile travma açısından ele alınması,

- Hemşirelerin çocuklarda kullanılan düşme riski değerlendirme ölçeklerini kullanma ve sonuçlarını değerlendirmenin önemini belirten konulara ilişkin hizmet içi eğitim programlarına dahil edilmesi önerilmektedir.

\section{KAYNAKLAR}

1. American Psychiatric Association. Diagnostic and statistical manual of mental disorders: DSM-IV-TR. 4th Ed., Washington, DC; 2010.

2. Inouye SK. Delirium in older persons. N Engl J Med 2006;354(11):1157-65. doi:10.1056/NEJMra052321.

3. Khan BA, Zawahiri M, Campbell NL, Fox GC, Weinstein EJ, Nazir A, et al. Delirium in hospitalized patients: Implications of current evidence on clinical practice and future avenues for research-A systematic evidence review. J Hosp Med 2012;7(7):580-9. doi:10.1002/jhm.1949. 
4. National Clinical Guideline Centre. Delirium: Diagnosis, Prevention and Management. National Institute for Health and Clinical Excellence: Guidance. London: Royal College of Physicians (UK); 2010. Erişim: https://www.ncbi.nlm.nih.gov/pubmed/22319805. Erişim Tarihi: 20.06.2019.

5. Hall RJ, Meagher DJ, MacLullich AMJ. Delirium detection and monitoring outside the ICU. Best Pract Res Clin Anaesthesiol 2012;26(3):367-83. doi:10.1016/j.bpa.2012.07.002.

6. Kelly P, Frosch E. Recognition of delirium on pediatric hospital services. Psychosomatics 2012;53(5):446-51. doi:10.1016/j.psym.2012.04.012.

7. Godfrey A, Conway R, Leonard M, Meagher D, Ólaighin GM. Motion analysis in delirium: A discrete approach in determining physical activity for the purpose of delirium motoric subtyping. Med Eng Phys 2010;32(2):101-10. doi:10.1016/j.medengphy.2009.10.012.

8. Antoon AY, Volpe JJ, Crawford JD. Burn encephalopathy in children. Pediatrics 1972;50(4):609-16.

9. Turkel SB, Tavare CJ. Delirium in children and adolescents. J Neuropsychiatry Clin Neurosci 2003;15(4):431-5. doi:10.1176/jnp.15.4.431.

10. Schieveld JNM, Leroy PLJM, Van Os J, Nicolai J, Vos GD, Leentjens AFG. Pediatric delirium in critical illness: Phenomenology, clinical correlates and treatment response in 40 cases in the pediatric intensive care unit. Intensive Care Med 2007;33(6):1033-40. doi:10.1007/s00134-007-0637-8.

11. Silver G, Traube C, Kearney J, Kelly D, Yoon MJ, Nash Moyal W, et al. Detecting pediatric delirium: Development of a rapid observational assessment tool. Intensive Care Med 2012;38(6):1025-31. doi:10.1007/s00134-012-2518-z.

12. Colville G, Kerry S, Pierce C. Children's factual and delusional memories of intensive care. Am J Respir Crit Care Med 2008;177(9):976-82. doi:10.1164/rccm.200706-857OC.7.

13. Smith HAB, Boyd J, Fuchs DC, Melvin K, Berry P, Shintani A, et al. Diagnosing delirium in critically ill children: Validity and reliability of the Pediatric Confusion Assessment Method for the Intensive Care Unit. Crit Care Med 2011;39(1):150-7. doi:10.1097/CCM.0b013e3181feb489.

14. Kain ZN, Caldwell-Andrews AA, Maranets I, McClain B, Gaal D, Mayes LC, et al. Preoperative anxiety and emergence delirium and postoperative maladaptive behaviors. Anesth Analg 2004;99(6):1648-54. doi:10.1213/01.ANE.0000136471.36680.97.

15. Prugh DG, Wagonfeld S, Metcalf D, Jordan K. A clinical study of delirium in children and adolescents. Psychosomatic Medicine 1980;42(1 Suppl.):177-95.

16. Hatherill S, Flisher AJ, Nassen R. Delirium among children and adolescents in an urban sub-Saharan African setting. J Psychosom Res 2010;69(2):187-92. doi:10.1016/j.jpsychores.2010.01.011.

17. Staggs VS, Mion LC, Shorr RI. Assisted and unassisted falls: Different events, different outcomes, different implications for quality of hospital care. Jt Comm J Qual Patient Saf 2014;40(8):358-64. doi:10.1016/S1553-7250(14)40047-3.

18. Fujita Y, Fujita M, Fujiwara C. Pediatric falls: Effect of prevention measures and characteristics of pediatric wards. Jpn J Nurs Sci 2013;10(2):223-31. doi:10.1111/jjns.12004.

19. Almis H, Bucak IH, Konca C, Turgut M. Risk factors related to caregivers in hospitalized children's falls. J Pediatr Nurs 2017;32:3-7. doi:10.1016/j.pedn.2016.10.006. 
20. Oliver D, Daly F, Martin FC, McMurdo MET. Risk factors and risk assessment tools for falls in hospital in-patients: A systematic review. Age Ageing 2004;33(2):122-30. doi:10.1093/ageing/afh017.

21. Kingston F, Bryant T, Speer K. Pediatric falls benchmarking collaborative. J Nurs Adm 2010;40(6):28792. doi:10.1097/NNA.0b013e3181df10d9.

22. Neiman J, Rannie M, Thrasher J, Terry K, Kahn MG. Development, implementation, and evaluation of a comprehensive fall risk program. J Spec Pediatr Nurs 2011;16(2):130-9. doi:10.1111/j.17446155.2011.00277.x.

23. Jamerson PA, Graf E, Messmer PR, Fields HW, Barton S, Berger A, et al. Inpatient falls in freestanding children's hospitals. Pediatric Nursing 2014;40(3):127-35.

24. McNeely HL, Thomason KK, Tong S. Pediatric Fall Risk Assessment Tool Comparison and Validation Study. J Pediatr Nurs 2018;41:96-103. doi:10.1016/j.pedn.2018.02.010.

25. Morse JM. Enhancing the safety of hospitalization by reducing patient falls. Am J Infect Control 2002;30(6):376-80. doi:10.1067/mic.2002.125808.

26. Demir D, Yöntem SÇ, Sarı HY, Bektaş M. Development of Diagnostic Falling Risk Scale for Child Patients. SANERC 2013;10(3):34-41.

27. Demir D, Çevik Yöntem S, Yıldırım Sarı H, Bektaş M. Çocuk hastalar için BUÇH düşme riski tanılama ölçeğinin geliştirilmesi. 1st Ed. Beylik U, Önder Ö, Eds. Ankara: T. C. Sağlık Bakanlığı Tedavi Hizmetleri Genel Müdürlüğü; 2011. 2-16 p.

28. Graf E. Magnet Children's Hospitals: Leading Knowledge Development and Quality Standards for Inpatient Pediatric Fall Prevention Programs. J Pediatr Nurs: Nursing Care of Children and Families 2011;26(2):122-7. doi:10.1016/j.pedn.2010.12.007.

29. Hill-Rodriguez D, Messmer PR, Williams PD, Zeller RA, Williams AR, Wood M, et al. The Humpty Dumpty Falls Scale: A Case-Control Study. J Spec Pediatr Nurs 2009;14(1):22-32. doi:10.1111/j.17446155.2008.00166.x.

30. Rouse MD, Close J, Prante C, Boyd S. Implementation of the Humpty Dumpty Falls Scale: A QualityImprovement Project. J Emerg Nurs 2014;40(2):181-6. doi:10.1016/j.jen.2012.11.001.

31. Razmus I, Davis D. The epidemiology of falls in hospitalized children. Pediatric Nursing 2012;38(1):315.

32. Ryan-Wenger NA, Kimchi-Woods J, Erbaugh MA, LaFollette L, Lathrop J. Challenges and conundrums in the validation of pediatric fall risk assessment tools. Pediatric Nursing 2012;38(3):159-67.

33. DiGerolamo K, Davis KF. An integrative review of Pediatric Fall Risk Assessment Tools. J Pediatr Nurs 2017;34:23-8. doi:10.1016/j.pedn.2017.02.036.

34. Özden D, Karagözoğlu Ş, Kurukız S. Determination of Fall Risk According to Hendrich II and Morse Fall Scale: A pilot study. Journal of Anatolia Nursing and Health Sciences 2012;15(1):80-8.

35. Tanıl V, Çetinkaya Y, Sayer V, Avşar D, İskit Y. Evaluating fall risk. Sağlık Akademisyenleri Dergisi 2014;1(1):21-6.

36. T.C. Sağlık Bakanlığı Sağlıkta Verimlilik Kalite ve Akreditasyon Dairesi Başkanlığı. İtaki Düşme Riski Değerlendirme Ölçeği. 2017. Erişim: https://kalite.saglik.gov.tr/TR,13486/itaki-dusme-riski-olcegi.html. Erişim Tarihi: 17.11.2019. 
37. Yöntem S, Gök D, Sarı HY, Güntürkün FA. BUÇH II Fall risk scale in children patients: Comparison with Harizmi and BUÇH Scale. İzmir Dr Behçet Uz Çocuk Hast Dergisi 2017;7(2):105-17. doi:10.5222/buchd.2017.105.

38. T.C. Sağlık Bakanlığı Sağlıkta Verimlilik Kalite ve Akreditasyon Dairesi Başkanlığı. Harizmi Düşme Riski Ölçeği. 2017. Erişim: https://kalite.saglik.gov.tr/TR,13485/harizmi-dusme-riski-olcegi.html. Erişim Tarihi: 17.11.2019.

39. Arend E, Christensen M. Delirium in the intensive care unit: A review. Nurs Crit Care 2009;14(3):14554. doi: $10.1111 / \mathrm{j} .1478-5153.2008 .00324 . x$.

40. Özdemir L. Yoğun bakım hastasında deliryumun yönetimi ve hemşirenin sorumlulukları. Hacettepe Üniversitesi Hemşirelik Fakültesi Dergisi 2014;1(1):90-8.

41. Devlin JW, Fong JJ, Howard EP, Skrobik Y, McCoy N, Yasuda C, et al. Assessment of delirium in the intensive care unit nursing practices and perceptions. Am J Crit Care 2008;17(6):555-66.

42. Wells LG. Why don't intensive care nurses perform routine delirium assessment? A discussion of the literature. Aust Crit Care 2012;25(3):157-61. doi: 10.1016/j.aucc.2012.03.002.

43. Morandi A, Jackson JC. Delirium in the intensive care unit: A review. Neurol Clin 2011;29(4):749-63. doi: 10.1016/j.ncl.2011.08.004.

44. Boot R. Delirium: A review of the nurses role in the intensive care unit. Intensive Crit Care Nurs 2012;28(3):185-9. doi: 10.1016/j.iccn.2011.11.004.

45. Guo-hao X, Xiang-ming F. Importance of recognizing and managing delirium in intensive care unit. Chin J Traumatol 2009;12(6):370-4. 